\title{
Motor Efficiency and Comparison of Children in Early Childhood from Greece Albania and Sweden
}

Zaragas K. Harilaos ${ }^{1}$, Sarris Demetrius ${ }^{1}$, Pliogou Vassiliki ${ }^{2}$, Ntella Dimitra ${ }^{1}$, Panagiotopoulou Antonia ${ }^{1}$ and Zioga $\mathrm{Olga}^{1}$

1. Department of Early Childhood Education (E.C.E.D.U.), University of Ioannina, Northwest Greece 45110, Greece

2. Department of Early Childhood Studies \& Special Education, Metropolitan College of Thessaloniki, Central Macedonia 56431,

Greece

\begin{abstract}
The purpose of this study was to observe record and compare the children's of early childhood performance of motor skills of different nationalities from Greece, Albania and Sweden. Additionally to investigate differences in motor performance between boys and girls and between age groups. The survey was conducted in the school years 2013-2014 and 2014-2015, and took place in the frame of the student exchange program ERASMUS internships of Preschool Education, University of Ioannina. The sample consisted of 369 infants (187 boys, 182 girls) aged $66 \pm 7$ months. The sample was selected according to the access that the team had in nursery schools of Ioannina (N1 = 133), in Dervitsani (N2 = 131) Albania and Gothenburg (N2 = 105) of Sweden. The array of 18 different motor activities for children aged 4-6 years old was used to investigate the toddlers' degree of movement performance. They were used the manufacturer's instructions for the degree of movement performance and classification of the sample in different categories, while a descriptive statistics and analysis of variance (Three Way ANOVA) took place for sex factors, age and region of origin. The results showed that although there were differences in rates distributions and averages, there were no significant differences either between children from the three countries or between boys and girls, however, there were in the age groups with older children who achieved better rates.
\end{abstract}

Key words: Motor development, motor efficiency, preschool age, MOT Test.

\section{Introduction}

Research Series [1-10] support that in parallel to the child's participation in the kinetics action through the process of physical activity and game, it was observed a positive effect on other areas of development such as mental, emotional and social ones. Berk [11, 12] argues that the development of a child's domain has an effect on the others too.

The development of motor skills in early childhood is of eminent importance, as the inability to develop and refine basic skills leads children to despair and failure during adolescence and adulthood in social-adaptive behavior [5, 13]. The movement through the physical activity has an important role to

Corresponding author: Zaragas K. Harilaos, Ph.D., assistant professor, research field: kinetic learning and education. children's physical, motor, emotional, social and cognitive development $[2,5,14-18]$. Childhood is one of the most critical periods of our lives. Then they are adopted habits-attitudes which can affect positively or negatively, our health [19].

The neuro-developmental disorders affect mobility, cognitive-adaptive development and communication skills of children. Many children live in psychosocial disadvantaged backgrounds because of poverty, weak family status (low economic and educational parental level, parental mental illness, substance abuse), as well as children who were born prematurely (seven months) or of very low birth weight (1001-1500 grams or less) present reduced motor performance.

An important fact is considered to be the choice of a suitable tool and evaluation measure of the motor development of children of early childhood for 
children's examination procedure. The measuring tool should be directed to the purpose of the test and be suitable to the developmental characteristics of the child. The proven reliability and validity of the measurement tool of motor development is an important factor for its selection [20]. According to Kambas et al. [21], the array of eighteen motor tests MOT test 4-6 years old of Zimmer and Volkamer [22], seems to be a valuable assessment tool of kinetic development for preschool children from Greece. This array of motor tests has been used in many studies in Greek area of early childhood education by various researchers [21-25].

Seven hundred seventy-eight children aged 48-71 months from Greece took place in the study of Kambas et al. [21]. The results showed significant differences between the age groups with the highest scoring best rates coming from the younger age group, while rates in the tests accomplished by both boys and girls were almost similar. From rate comparisons accomplished by Greek children to those of infants from Germany there were no significant differences between the respective age groups, although children from the German sample appeared to have higher prices but not statistically significant than those of the Greek sample.

In another earlier study from Papadopoulos et al. [26] which was designed to compare the motor performance of 65 preschool children from Greece and 54 children of the same age from Germany, the results showed that the level of motor performance of children in Greece appears to be lower than that of the children in Germany which according to the researchers demonstrates the need for a more efficient development of motor skills in Greek kindergarten.

From the study of the research work, based on the performance of motor preschoolers' skills, it was found that there are few reports in the international scientific area and almost non-existent in Greece and those existed are associated with another variable such as the Body Mass Index [27-31], physical activity [21], social skills [1, 32-35] and developmental disorders of neuromuscular splice [15, 36, 37].

According to Pappas [38], in the Greek reality the course of physical education nor covers nor meets the needs of students, especially those of preschool and school education, as at that age they are based the fundamentals of kinetic therapy. Cooperation between countries in programmatic basis, Switzerland, Austria, Germany, Holland, Italy and Belgium was necessary to create a school with more movement. Students of the above countries reported problems and pains in spine and sacrum that came from students' static and sedentary behavior [38]. Apart from the family, the problem of the low level of children's motor performance also concerns the educational community that is extremely worried about the situation.

So these questions were created: what is the efficiency of motor skills of children of early childhood? What is the difference if any between the children of the same age from other countries? And also, what is the difference between boys and girls and different age groups of early childhood?

The purpose of this study was first to observe, record and compare the performance of motor skills which determine the children's of early childhood motor development of different nationalities from Greece, Albania and Sweden, and secondly the investigation of differences in motor performance between boys and girls, and age groups.

\section{Conceptual Definitions}

Motor development is the lifelong progressive change in motor behavior, which takes place under conditions of interaction of the requirements imposed by the individual actions, of his individual biological capabilities and environmental conditions [13].

Motor efficiency is an indicator of motor development. It is determined by the performance on different qualitatively aspects of fine and gross motor development [39]. The motor performance is the score that gets in the MOT test each child and it is equal to the sum of seventeen individual testing's according to 
the manufacturers.

Kinetic Skill is the fundamental motor pattern, which is accurately performed with accuracy, control, economy of forces and in possible short time [13].

\section{Sample}

Then, in Table 1, it is presented the sample of the children regarding the characteristics of gender, age and the town of research. The sample consisted of 369 infants (187 boys, 182 girls) aged $66 \pm 7$ months old which were selected by the method of random sampling while the three cities were selected in accordance with the approach of the team through Programs (ERASMUS). The sample was selected from public kindergartens of Ioannina $(\mathrm{N} 1=133)$, Dervitsani $(\mathrm{N} 2=131)$ from Albania and Gothenburg $(\mathrm{N} 2=105)$ of Sweden.

\section{Method}

To measure the kinetic efficiency in infancy of four to six years old, it was used the array of kinetic assays "MOT 4-6 (Motoriktest für vier- bis sechsjährige Kinder)" of Zimmer et al. [22]. This array consists of 18 motor tests which assess children's motor performance aged four to six years. According to the criteria and the manufacturer's instructions [22], kinetic assays generally evaluate the motor development and specific agility and visual kinetic coordination (fine and gross motor), the dynamic balance, reaction speed, speed motion, motor control, the jumping ability generally representing the three skills of movement in space, balance (static and dynamic) and object manipulation.

Kinetic assays refer to actions that the child has to perform, namely: first test jump with both feet into hoop without touching it and then jump out of it in the same direction. This test is not evaluated and it is considered as experimental, 2nd test, walking distance within a specified length and width $(2 \mathrm{~m} \times 0.1 \mathrm{M})$, third test, to make dots with a pen on a sheet of paper, 4th test, to catch a scarf with toes, fifth test, to make lateral jumps with both feet, sixth test, to catch a rod that falls, seventh test, to carry three tennis balls in a box from a distance of 4 meters, eighth test, walk upside back within a certain distance in length and width $(2 \mathrm{~m} \times$ $0.1 \mathrm{M})$, ninth test, throw a tennis ball to a target, 10th test, to collect 40 matchsticks in a box from the table with both hands simultaneously, 11th test, pass through a hoop, 12th test, doing jumping on one foot inside the hoop and remain motionless on one leg, 13th test, catch a link, 14th test, doing puppet jumps, i.e. feet in dimension hands to uplift and then bringing foot and hand close repeatedly for some time, 15 test, to jump over a rope of $35 \mathrm{~cm}, 16$ test, make scrollbars, somersault, 17th test, do lift chair from a squatting position with ball holding with both hands over his head, and 18th test, to leap with half turn from the outside through the rim and then the same coming out of the hoop.

The performance in each of the 18 test movements is attributable in various ways. The primary results of the tests as the number of jumps made, the seconds it took to complete the test are recorded and then converted to a three-level rating scale. In this way, the individual

Table 1 The characteristics of the research sample regarding gender, area and age in months $(\mathrm{N}=369,100 \%)$.

\begin{tabular}{lllll}
\hline \multirow{2}{*}{ Gender } & & Value Label & $\mathrm{N}$ & $\%$ \\
& 1 & Boys & 187 & 50.7 \\
\multirow{2}{*}{ Age } & 2 & Girls & 182 & 49.3 \\
& 1 & $48-54$ months & 97 & 26.3 \\
& 2 & $55-61$ months & 124 & 33.6 \\
\multirow{2}{*}{ Country } & 3 & $62-68$ months & 148 & 40.1 \\
& 1 & Ioannina greece & 133 & 36 \\
& 2 & Dervitsani albania & 131 & 35.5 \\
\hline
\end{tabular}


performance of the child varies from 0 (the child did not succeed) to 1 (to child did not succeed fully) to two (the child succeeded). The rating of the motor performance or degree of movement performance can range from 0 to 34 and indicates the child's motor development. According to the criteria and the manufacturer's instructions [22], a standard norm kinetic data is provided which is defined for each age level and based on a standard database of 548 children and determines the outcome in five levels (very good, good, normal, below normal, obvious motor weaknesses).

\section{Procedure}

Kinetic tests and their infrastructure were presented with the form of game after a short story had been told for a better approach from the side of children so that they can cooperate and attribute the maximum kinetic performance. For example, from the first test to the 18th, the child is asked to find the hidden treasure through an adventurous and symbolic crossing mountain, lake, river, bridge, and cave. The child will need to jump over river rocks, to cross paths in the woods and do various, maneuvers to throw stones on the target to achieve the fruits of the forest, to transport, to walk on a narrow bridge, pass through a cave to help the dwarves collect the tree trunks (matchsticks), step on the lilies of a pond until it discovers the hidden treasure which was a box that was inside a mirror. Finding the mirror meant the completion of 18 the arrays of the MOT tests. At the end of the test, each child was getting the thumbs up from the other children and the kindergartener. The kindergarten teacher subsequently explained to the child that the treasure is this same child and the effort paid and managed to complete the adventure. All measurements were made during the operation of the nursery school years 2013-2014 and 2014-2015 by the research team and in collaboration with the kindergarten teachers who had attended a relative seminar on the array of motor trials of MOT test, and on the condition that information and consultation with the toddlers' parents had been made.

\section{Statistical Analysis}

There were made tables of frequency distribution and the corresponding rates for the survey variables (Table 2), frequency allocations and the relative percentages of the values (Table 3), frequency distribution of values of Grade Kinetic Growth (Table 4), as well as lists of their descriptive data (mean, standard deviation, see Table 5). Conducted analysis of variance ( 3 Way-ANOVA, see Tables 6 and 7) with independent variables (gender $\mathrm{X} 2 *$ age $\mathrm{X} 3 *$ range $\mathrm{X} 3)$.

\section{Results}

Table 2 summarizes the results of the tests, the frequencies and the corresponding figures in the scores achieved by all children in the sample $(\mathrm{N}=369,100 \%)$, according to the MOT test manufacturers with a minimum price " 8 " and maximum of " 34 " rate.

Table 3 is a presentation of the levels of motor performance with respect to the country of origin. Overall for the survey sample, it seems that 89 children (24.1\%) is at a very good level, 110 children (29.8\%) are at a good level, 158 children $(42.8 \%)$ are at the normal level of motor performance, 8 children (2.2\%) are under normal and 4 children $(1.1 \%)$ had overt motor weaknesses and need urgent intervention to improve their motor skills programs.

Table 4 presents the motor performance levels according to the variables of sex, age and country of origin while Table 5 below shows in detail according to the characteristics of the sample, the descriptive statistical analysis (mean, standard deviation) of motor performance.

The triple unassociated ( 3 Way ANOVA, see Table 6) showed that: (1) There is no significant effect of the area $(\mathrm{F}=1.79, P=0.168$, see Table 6$)$. It appears that the three areas do not differ significantly in their performance in the MOT test; (2) There is no significant effect of gender $(\mathrm{F}=0.57, P=0.448$, see 
Table 6), it seems that the boys did not differ significantly in their performance in the MOT test compared to girls; (3) There is no significant interaction between gender and area $(\mathrm{F}=0.12, P=$ 0.879 , see Table 6); (4) There is a significant effect of age $(\mathrm{F}=33.71, P=0.001$, see Table 6). Control Scheffe showed that the older age group (62-68 months old) achieves better average degree of kinetic growth $($ Mean $=29.72$, St.Dv. $=4.79, \mathrm{~N}=148$, see Table 5) and differs significantly $(P=0.003$, see Table 7$)$ than

Table 2 Frequency allocations of the values achieved by the children of the sample $(N=369,100 \%)$ in the MOT Test tests according to region, age (48-54, 55-61, 62-68 months) and gender $(B=b o y, G=$ girls).

\begin{tabular}{|c|c|c|c|c|c|c|c|c|c|c|c|c|c|c|c|c|c|c|c|}
\hline \multirow{2}{*}{\multicolumn{2}{|c|}{ MOT-test }} & \multicolumn{6}{|c|}{ Ioannina GREECE } & \multicolumn{6}{|c|}{ Dervitsani ALBANIA } & \multicolumn{6}{|c|}{ Goteborg SWEDEN } \\
\hline & & \multicolumn{2}{|c|}{$48-54$} & \multicolumn{2}{|c|}{$55-61$} & \multicolumn{2}{|c|}{$62-68$} & \multicolumn{2}{|c|}{$48-54$} & \multicolumn{2}{|c|}{$55-61$} & \multicolumn{2}{|c|}{$62-68$} & \multicolumn{2}{|c|}{$48-54$} & \multicolumn{2}{|c|}{$55-61$} & \multicolumn{2}{|c|}{$62-68$} \\
\hline Skor & $\mathrm{f}$ & $\mathrm{B}$ & G & B & G & $\mathrm{B}$ & G & $\mathrm{B}$ & G & B & $\mathrm{G}$ & B & G & B & G & B & $\mathrm{G}$ & B & G \\
\hline 8 & 4 & 2 & & & & & & 1 & & & & & & 1 & & & & & \\
\hline 11 & 5 & & & & & & & 2 & & & & & & 3 & & & & & \\
\hline 12 & 2 & & & & & & & 2 & & & & & & & & & & & \\
\hline 14 & 1 & & & & & & & 1 & & & & & & & & & & & \\
\hline 16 & 24 & 4 & 3 & 1 & 3 & & & 4 & 2 & 1 & 3 & & & 3 & & & & & \\
\hline 17 & 5 & & & 1 & & & & & 1 & 2 & 1 & & & & & & & & \\
\hline 18 & 4 & & & & & & 1 & & & & & & 2 & & & & 1 & & \\
\hline 19 & 1 & & & & & & & & & & & & & 1 & & & & & \\
\hline 20 & 4 & & 1 & & & & 1 & & 1 & & & & & 1 & & & & & \\
\hline 21 & 6 & & 1 & & & 2 & & 1 & & & & & & 1 & 1 & & & & \\
\hline 22 & 30 & 1 & 2 & 4 & 3 & & 2 & 2 & 5 & 2 & 4 & & 1 & 1 & 2 & & & & 1 \\
\hline 23 & 25 & 1 & & & 2 & 1 & 3 & & & 3 & 1 & 2 & 3 & & & 3 & 5 & & 1 \\
\hline 24 & 20 & 1 & & & & 1 & 3 & & 1 & & 1 & 3 & 2 & & 1 & 1 & & 3 & 3 \\
\hline 25 & 10 & & 1 & & 1 & 1 & 1 & & & 2 & 2 & & & & & & & 1 & 1 \\
\hline 26 & 16 & 2 & 1 & 3 & & & & & & & 1 & 1 & 1 & & & 2 & 1 & 2 & 2 \\
\hline 27 & 13 & 1 & & 2 & 2 & 1 & & & & 2 & 1 & 1 & & & & 1 & 1 & 1 & \\
\hline 28 & 19 & 3 & 3 & & & & 1 & 2 & 2 & & 1 & & 3 & 2 & & & & & \\
\hline 29 & 10 & & & 1 & 1 & 1 & & & & 1 & & 1 & & & & 2 & 1 & 1 & 3 \\
\hline 30 & 20 & 1 & 4 & & & 4 & 1 & 3 & 2 & & 1 & 2 & & 1 & & 1 & & & \\
\hline 31 & 6 & & & & & 1 & 1 & 1 & & & & 1 & & & & & & 2 & \\
\hline 32 & 42 & 2 & & 6 & 5 & 4 & 2 & & 1 & 5 & 2 & 3 & 3 & 2 & 3 & & 2 & 1 & 1 \\
\hline 33 & 13 & & & & & 1 & & & 1 & 1 & & 2 & 3 & 2 & 1 & 1 & & & 1 \\
\hline 34 & 89 & & & 4 & 7 & 10 & 10 & 2 & & 4 & 3 & 7 & 9 & & & 7 & 5 & 11 & 10 \\
\hline Total & 369 & 18 & 16 & 22 & 24 & 27 & 26 & 21 & 16 & 23 & 21 & 23 & 27 & 18 & 8 & 18 & 16 & 22 & 23 \\
\hline
\end{tabular}

Table 3 Frequency allocations and the relative percentages of the values accomplished by the sample children $(\mathrm{N}=369,100 \%)$ at various levels in the MOT tests.

\begin{tabular}{|c|c|c|c|c|c|c|c|c|c|}
\hline \multirow{2}{*}{ MOT Test } & \multirow{2}{*}{ Level } & \multicolumn{2}{|c|}{$\begin{array}{c}\text { Ioannina } \\
\text { Greece }\end{array}$} & \multicolumn{2}{|c|}{$\begin{array}{c}\text { Dervitsani } \\
\text { Albania }\end{array}$} & \multicolumn{2}{|c|}{$\begin{array}{c}\text { Goeteborg } \\
\text { Sweden }\end{array}$} & \multicolumn{2}{|c|}{ Total } \\
\hline & & $\mathrm{N}$ & $\%$ & $\mathrm{~N}$ & $\%$ & $\mathrm{~N}$ & $\%$ & $\mathrm{~N}$ & $\%$ \\
\hline 34 & Very well & 31 & $\begin{array}{l}23.3 \\
8.4\end{array}$ & 25 & $\begin{array}{l}19.1 \\
6.8\end{array}$ & 32 & $\begin{array}{l}30.5 \\
8.7\end{array}$ & 89 & 24.1 \\
\hline $33-28$ & Well & 42 & $\begin{array}{l}31.6 \\
11.4\end{array}$ & 39 & $\begin{array}{l}29.8 \\
10.6\end{array}$ & 27 & $\begin{array}{l}25.7 \\
7.3\end{array}$ & 110 & 29.8 \\
\hline $27-15$ & Normal & 58 & $\begin{array}{l}43.6 \\
15.7\end{array}$ & 61 & $\begin{array}{l}46.6 \\
16.5\end{array}$ & 42 & $\begin{array}{l}40 \\
11.4\end{array}$ & 158 & 42.8 \\
\hline $14-9$ & Under normal & & & 5 & $\begin{array}{l}3.8 \\
1.4\end{array}$ & 3 & $\begin{array}{l}2.9 \\
0.8\end{array}$ & 8 & 2.2 \\
\hline $8-0$ & Kinetic weakness & 2 & $\begin{array}{l}1.5 \\
0.5\end{array}$ & 1 & $\begin{array}{l}0.8 \\
0.3\end{array}$ & 1 & $\begin{array}{l}0.8 \\
0.3\end{array}$ & 4 & 1.1 \\
\hline Total & & 133 & $\begin{array}{l}100 \\
36\end{array}$ & 131 & $\begin{array}{l}100 \\
35.5\end{array}$ & 105 & $\begin{array}{l}100 \\
28.5\end{array}$ & 369 & 100 \\
\hline
\end{tabular}


Table 4 Frequency distribution of values of Grade Kinetic Growth achieved by the sample children $(N=369,100 \%)$ at different classification levels*.

\begin{tabular}{|c|c|c|c|c|c|c|c|c|c|}
\hline \multirow{2}{*}{ Country } & \multirow{2}{*}{ MOT Test Level } & \multicolumn{2}{|c|}{ 48-54 Months } & \multicolumn{2}{|c|}{ 55-61 Months } & \multicolumn{2}{|c|}{ 62-68 Months } & \multicolumn{2}{|c|}{ Total } \\
\hline & & Boys & Girls & Boys & Girls & Boys & Girls & Boys & Girls \\
\hline \multirow{6}{*}{ Ioannina Greece } & Very well & & & 4 & 7 & 10 & 10 & 14 & 17 \\
\hline & Well & 6 & 7 & 7 & 6 & 11 & 5 & 24 & 18 \\
\hline & Normal & 10 & 9 & 11 & 11 & 6 & 11 & 27 & 31 \\
\hline & Under normal & & & & & & & & \\
\hline & Kinetic weakness & 2 & & & & & & 2 & \\
\hline & Total & 18 & 16 & 22 & 24 & 27 & 26 & 67 & 66 \\
\hline \multirow{6}{*}{$\begin{array}{l}\text { Dervitsani } \\
\text { Albania }\end{array}$} & Very well & 2 & & 4 & 3 & 7 & 9 & 13 & 12 \\
\hline & Well & 6 & 6 & 7 & 4 & 9 & 9 & 22 & 19 \\
\hline & Normal & 7 & 10 & 12 & 14 & 7 & 9 & 26 & 33 \\
\hline & Under normal & 3 & 2 & & & & & 3 & 2 \\
\hline & Kinetic weakness & 1 & & & & & & & \\
\hline & Total & 19 & 18 & 23 & 21 & 23 & 27 & 65 & 66 \\
\hline \multirow{7}{*}{$\begin{array}{l}\text { Goeteborg } \\
\text { Sweden }\end{array}$} & Very well & & 1 & 7 & 4 & 11 & 10 & 19 & 14 \\
\hline & Well & 7 & 4 & 4 & 3 & 4 & 5 & 15 & 12 \\
\hline & Normal & 6 & 5 & 7 & 8 & 7 & 8 & 20 & 21 \\
\hline & Under normal & 1 & 2 & & & & & 1 & 2 \\
\hline & Kinetic weakness & & & 1 & & & & 1 & \\
\hline & Total & 14 & 12 & 19 & 15 & 22 & 23 & 55 & 50 \\
\hline & Total & 51 & 46 & 64 & 60 & 72 & 76 & 187 & 182 \\
\hline
\end{tabular}

*The value that the child achieves in accordance with manufacturers [44] for each level are: (1) "very well" only the value 34; (2) for "well" the value range is from 33 to 28; (3) for the level "normal" the value range is between 27 and 16; (4) for "under normal" the value ranges from 15 to 9 and (5) "Kinetic Weakness" value ranges from 8 and below.

Table 5 The descriptive characteristics (Means, St. Deviation, N) of the survey sample regarding gender, region and age in months $(\mathrm{N}=369,100 \%)$.

\begin{tabular}{|c|c|c|c|c|c|c|c|c|c|c|c|c|c|}
\hline \multirow[b]{2}{*}{ Country } & \multirow[b]{2}{*}{ Gender } & \multicolumn{3}{|c|}{ 48-54 Months } & \multicolumn{3}{|c|}{ 55-61 Months } & \multicolumn{3}{|c|}{ 62-68 Months } & \multicolumn{3}{|c|}{ Total } \\
\hline & & Means & $\begin{array}{l}\text { St. } \\
\text { Dev. }\end{array}$ & $\mathrm{N}$ & Means & $\begin{array}{l}\text { St. } \\
\text { Dev. }\end{array}$ & $\mathrm{N}$ & Means & $\begin{array}{l}\text { St. } \\
\text { Dev. }\end{array}$ & $\mathrm{N}$ & Means & $\begin{array}{l}\text { St. } \\
\text { Dev. }\end{array}$ & $\mathrm{N}$ \\
\hline \multirow{3}{*}{$\begin{array}{l}\text { Ioannina } \\
\text { Greece }\end{array}$} & Boys & 22.56 & 7.53 & 18 & 27.68 & 5.60 & 22 & 30.44 & 4.21 & 27 & 27.42 & 6.46 & 67 \\
\hline & Girls & 24.25 & 5.29 & 16 & 27.71 & 6.36 & 24 & 28.50 & 5.53 & 26 & 27.18 & 5.95 & 66 \\
\hline & Total & 23.35 & 6.53 & 34 & 27.70 & 5.94 & 46 & 29.49 & 4.96 & 53 & 27.30 & 6.19 & 133 \\
\hline \multirow{3}{*}{$\begin{array}{l}\text { Dervitsani } \\
\text { Albania }\end{array}$} & Boys & 22.05 & 8.36 & 19 & 27.17 & 5.98 & 23 & 30.04 & 4.12 & 23 & 26.69 & 6.95 & 65 \\
\hline & Girls & 22.61 & 6.59 & 18 & 25.10 & 6.03 & 21 & 29.11 & 5.40 & 27 & 26.06 & 6.46 & 66 \\
\hline & Total & 22.32 & 7.45 & 37 & 26.18 & 6.02 & 44 & 29.54 & 4.83 & 50 & 26.37 & 6.69 & 131 \\
\hline \multirow{3}{*}{$\begin{array}{l}\text { Goeteborg } \\
\text { Sweden }\end{array}$} & Boys & 24.36 & 7.37 & 14 & 28.37 & 6.58 & 19 & 30.59 & 4.07 & 22 & 28.24 & 6.33 & 55 \\
\hline & Girls & 24.17 & 8.48 & 12 & 27.67 & 5.38 & 15 & 29.83 & 4.53 & 23 & 27.82 & 6.23 & 50 \\
\hline & Total & 24.27 & 7.74 & 26 & 28.06 & 6.00 & 34 & 30.20 & 4.28 & 45 & 28.04 & 6.26 & 105 \\
\hline Boys & & 22.86 & 7.71 & 51 & 27.70 & 5.96 & 64 & 30.36 & 4.09 & 72 & 27.41 & 6.59 & 187 \\
\hline Girls & & 23.59 & 6.63 & 46 & 26.78 & 6.04 & 60 & 29.12 & 5.16 & 76 & 26.95 & 6.22 & 182 \\
\hline Total & & 23.21 & 7.19 & 97 & 27.26 & 5.99 & 124 & 29.72 & 4.70 & 148 & 27.18 & 6.41 & 369 \\
\hline
\end{tabular}

the group (55 to 61 months) as well $(P=0.001$, see Table 7) than the younger group of the sample (48 to 54 months old). The group (55-61 months old) achieves better average degree of kinetic growth (Mean $=27.26$, St.Dv. $=5.99, \mathrm{~N}=124$, see Table 5) and differs significantly $(P=0.001$, see Table 7$)$ than (48-54 months old) age group $($ Mean $=23.21$, St.Dv. $=7.19$, $\mathrm{N}=97$, see Table 5); (5) There is no significant interaction between age and the area ( $f=0.29, P=$ 0.882 , see Table 6); (6) There is no significant interaction 
Table 6 Summary table analysis of variance $(N=369,100 \%)$.

\begin{tabular}{llllll}
\hline Source & Type III Sum of Squares & df & Mean Square & F & Sig. \\
\hline Country & 126.1 & 2 & 63.05 & 1.79 & 0.168 \\
Gender & 20.33 & 1 & 20.33 & 0.57 & 0.448 \\
Age & 2370.96 & 2 & 1185.48 & 33.71 & 0.001 \\
Country * Gender & 9.06 & 2 & 4.53 & 0.12 & 0.879 \\
Country * Age & 41.36 & 4 & 10.34 & 0.29 & 0.882 \\
Gender * age & 56.02 & 2 & 28.01 & 0.79 & 0.452 \\
Country * Gender * age & 43.03 & 4 & 10.75 & 0.30 & 0.874 \\
Error & 12343.56 & 351 & 35.16 & & \\
\hline
\end{tabular}

Table 7 Summary table (post hoc) of multiple comparison control (Scheffe) for the factor of the sample age $(\mathrm{N}=369,100 \%)$.

\begin{tabular}{lllllll}
\hline \multirow{2}{*}{ Age } & Age & Mean Difference (I-J) & Std. Error & $P$ & \multicolumn{2}{c}{ Confidence Interval } \\
\cline { 5 - 7 } & & & & & Lower Bound & Upper Bound \\
\hline \multirow{2}{*}{ 48-54 Months } & 55-61 Months & -4.05 & 0.804 & 0.001 & -6.03 & -2.08 \\
& 62-68 Months & -6.52 & 0.775 & 0.001 & -8.42 & -4.61 \\
\hline \multirow{2}{*}{ 55-61 Months } & 48-54 Months & 4.05 & 0.804 & 0.001 & 2.08 & 6.03 \\
& 62-68 Months & -2.46 & 0.722 & 0.003 & -4.24 & 8.42 \\
\hline \multirow{2}{*}{ 62-68 Months } & 48-54 Months & 6.52 & 0.775 & 0.001 & 4.61 & 4.24 \\
\hline
\end{tabular}

Based on observed means. The error term is Mean Square (Error) $=35,167$. The mean difference is significant at the 0.05 level.

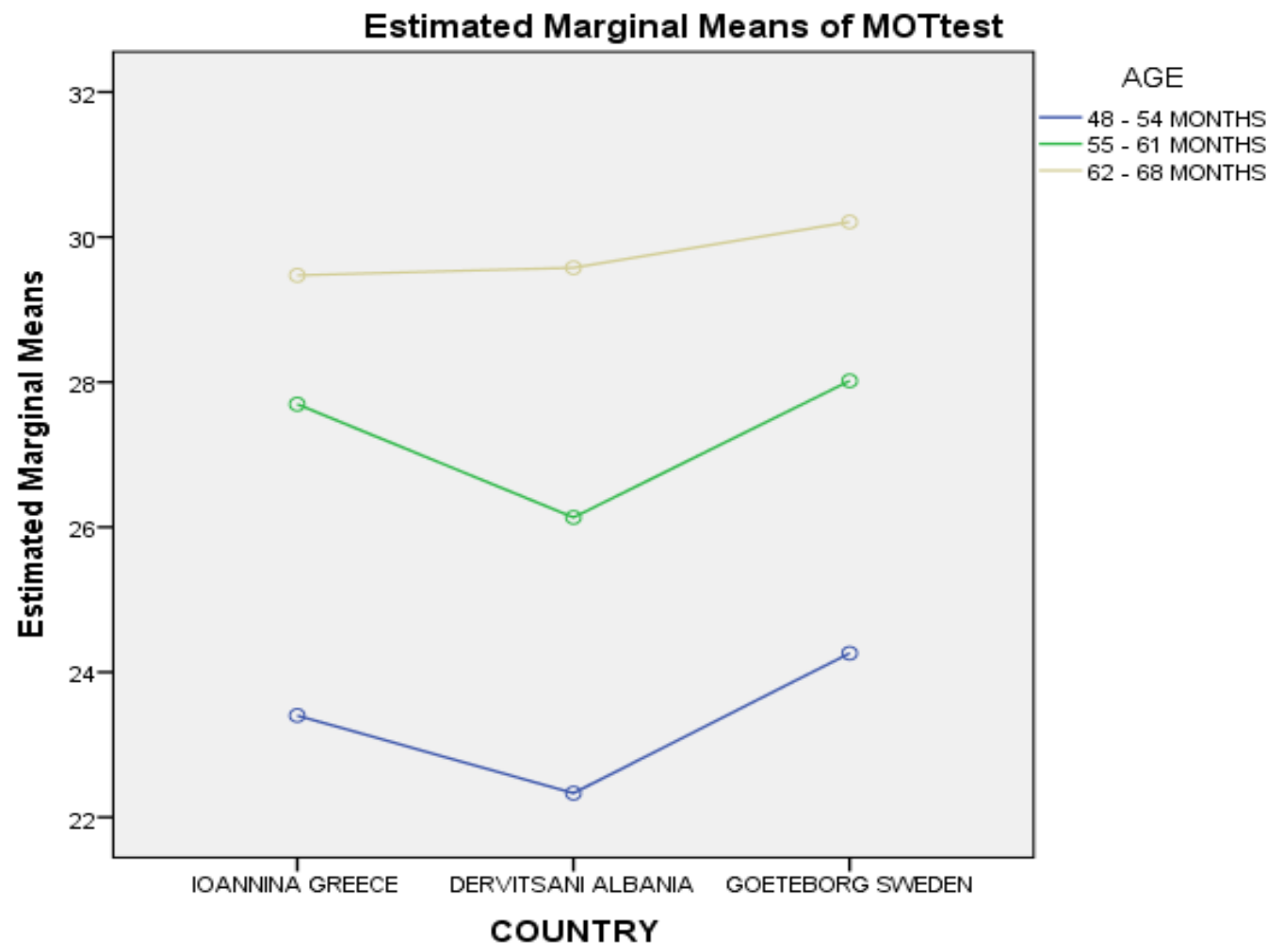




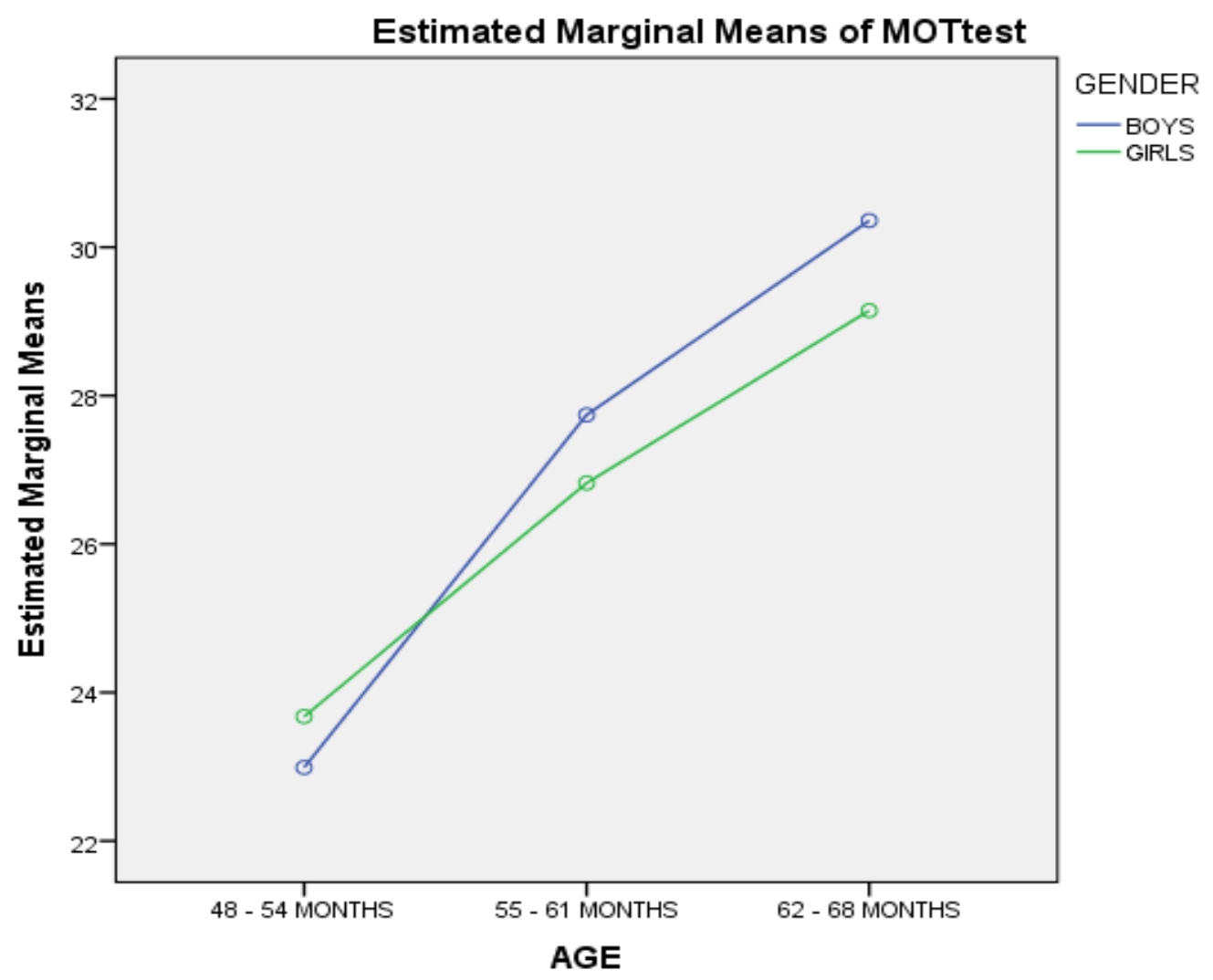

Fig. 1 Graphic display of average motor performance of children on the country of origin, sex and age group

between gender and age ( $f=0.79, P=0.452$, see Table 6 ), and (7) There is no significant interaction between area, gender and age range $(\mathrm{F}=0.30, P=0.874$, see Table 6).

In Fig. 1, they are presented by graphic representation the averages of the children's performance: (1) regarding the variables of town and age, and (2) regarding the age and the gender. In the first graphic representation, it is distinguished the difference in the performances related to the age and more specifically with the elder aged groups achieving better kinetically performances with statistically significant difference (Table 6). In the second graphic representation, it is distinguished the differences in performances between boys and girls in the groups of different age. The girls achieved better scores in the younger aged group (48-54 months), whereas the boys in the elder aged groups without statistically significant difference
(Table 6).

\section{Conclusions and Suggestions}

This research studied the kinetic performance of children of early childhood from Greece, Albania and Sweden, as well as the differences between boys and girls, and between age groups. Although the survey sample is not small $(\mathrm{N}=369)$, its results for the motor performance cannot be generalized for wider respective age populations of all children of early childhood for three countries. However, the results of this research can: (1) show us the general trend for the motor performance in this sample and thus it can be displayed a situation that may characterize the general population of infants in Greece, and (2) compare with results of previous and related future research.

The results showed that there are differences between the average motor performances that are not significant though. Specifically, children from 
Gothenburg, Sweden achieved higher average than children of Ioannina and these of Ioannina managed greater than those of Dervitsani.

The results of this study agree with respective researches [21, 40] made between children of early childhood from Greece and Germany. The results showed the existence of very small but not significant differences in motor performance in infants from the German region who achieved higher average motor performance. Kambas et al. [21] also showed that the battery-motor test [22] is a valuable tool motor performance to evaluate the kinetic development of early childhood children in Greece. On the contrary, Papadopoulos et al. [26] showed lower averages of children from Greece compared with those from Germany and suggested the direct support of intervention programs in Greek kindergarten. The research from Papadopoulos et al. [26] had a very small sample in relation to the present research and a different motor performance assessment tool.

Girls have a higher average in the motor performance in the younger age group (48-54 months old) while in the next two higher age groups (55-61 and 62-68 months old) boys present a higher average. These differences between boys and girls in each age group are not statistically significant. Rather significant are the differences in motor performance between age groups with the older age group scoring higher on average than the next younger age group. The findings of this study are consistent with the research findings $[21,27,28,40]$, that examined the influence of gender on motor development of children aged 4-6 years. The older children had better performance than younger ones while there were not significant differences between boys and girls.

The results of this study showed that girls did better in mating tests (jump puppet, passing through the hoop, balance) while boys did better in jumping tests without forums of throwing and response. They agree with the corresponding research results [41]. It was noted that boys performed better in terms of jumping ability and climbing stairs, while girls showed better performance in terms of bouncing.

The sample of this research in general, achieves a very high percentage of good motor performance values in both the fine and gross motor while a very small percentage show values below normal and apparent kinetic weaknesses which need immediate intervention of motor skill improvement programs. These children appeared at the representative samples of all three countries. Children who achieved values (good and very good, see Table 4) above normal in motor performance participated in their free time in regular sports activities (dance, ballet, rhythmic, football) and those not taking part in regular sporting activity pass long periods of free play. Another factor that affects the formation of the result is the implementation of the curricula of each country and the daily program that the kindergartener implements in the classroom. Through participant observation in the programs of all three areas, it seems that Sweden applies consistently and more organized the psychomotor education programs, sporting activities (swimming, gymnastics, and walks in the woods), educational actions that take place in the other two countries but not so systematically and scheduled on weekly base. The curriculum of both Greece and Albania emphasizes in physical education, interdisciplinary and psychomotor therapy but what generally occurs is that the focus of his/her kindergartener is on free play and the acquisition of useful knowledge against most of the time to physical activity which is limited by time, due to reduced infrastructure in suitably equipped gymnastic areas [42]. Research in Ioannina, Lefkada and Athens indicate that the majority of nurseries do not have a utility space or auxiliary room for individual play and motor activities, while almost half have a courtyard, the extent of which does not exceed 100 sq.m. [43]. In the literature review undertaken for the curricula of all three countries, there were not found many common elements on the promotion of psychomotor field and 
the implementation of physical education programs. The characteristics that form the motor performance and may need further investigation are the knowledge and its application by the kindergartener regarding physical education in the daily and weekly plan of kindergarten activities, logistics and space for physical education, the relationship between mother and father of a child with physical education, as well as physical activity in children's leisure time.

\section{References}

[1] Zaragas, Ch., Tsitsanoudi-Mallidi, N., and Aggelaki, A. 2013. "Motor Education and Vocabulary Development of Arithmetical and Geometrical Concepts in Kindergarten and Primary Education." In Language Learning and Assessment-Challenges and Implications, edited by Zhang, L. New York: Untested Ideas Research Center, Chapter 5, 89-111.

[2] Zaragkas, Ch. 2012. "Investigation of the Relationship between the Degree of Motor Learning and Social Action through Collective Motor Activities in Kindergarten." Practical Scientific Yearbook Early Childhood Department University of Ioannina School of Education (5): 5-30. Accessed February 10, 2016. http://www.uoi.gr/schools/earlychildhood/epetirida_paida gwgikou_tmimatos_nipiagwgwn_vol5.pdf

[3] Treflas, E., and Tsingilis, N. 2008. "Evaluation of the Effect of a Physical Education Program on Playful Behavior in Preschool Children: A Qualitative Approach." Inquiries in Physical Education and Sport 6 (1): 1-13.

[4] Goti, E., Derri, B., and Kioumourtzoglou, E. 2006. "Language Development Preschool Children through Physical Education." Inquiries in Physical Education \& Sport Volume 4 (3): 371-8.

[5] Gallahue, L. D. 2002. Developmental Physical Education for Today's Children, translated by Evangelinou, Chr., and Pappa, A. Thessaloniki: University Studio Press.

[6] Kieff, J., and Casbergue, R. 2000. Playful Learning and Teaching. Integrating Play in Preschool and Primary Programs. Boston: Allyn and Bacon.

[7] Barton, G., Kirby, K., Nazario, C., and Brooks, S. 2000. "Let's Speak Spanish in Physical Education. Integrating Spanish BSER Terms in Physical Education.” Teaching Elementary Physical Education 11 (1): 19-21.

[8] Van Hiele, P. 1999. "Developing Geometry Thinking through Activities That Begin with Play." Teaching Children Mathematics 5 (6): 310-6.

[9] Daley, D. 1988. "Language Development through
Physical Education." British Journal of Physical Education 19 (3): 132-3.

[10] Dummer, G., and Connor-Kuntz, F. 1996. "Teaching across the Curriculum: Language-Enriched Physical Education for Preschool Children." Adapted Physical Activity Quarterly 13 (3): 302-15.

[11] Berk, L. 2001. Child Development, 5th ed. Boston: Allyn $\&$ Bacon.

[12] Berk, L. 2002. Infants, Children and Adolescents. Boston: Allyn \& Bacon.

[13] Gallahue, D., and Ozmun, J. 1998. Understanding Motor Development: Infants, Children, Adolescents, and Adults. Singapore: Mc Graw Hill.

[14] GG 303B/13-03-2003 GG \& 304B/13-03-2003: Cross Curriculum Framework-Curriculum for Kindergarten (DEPPS-A.P.S.). Accessed March 14, 2015. www.pi-schools.gr/programs/depps/

[15] Giagazoglou, P., Kabitsis, N., Kokaridas, D., Zaragas, Ch., Katartzi, E., and Kabitsis, C. 2011. "The Movement Assessment Battery in Greek Preschoolers: The Impact of Age, Gender, Birth Order, and Physical Activity on Motor Outcome." Journal of Research in Developmental Disabilities 32 (6): 2577-82.

[16] Hagger, M. S., Hatzisarantis, N., and Biddle, S. 2001. "The Influence of Self-Efficacy and Past Behavior on the Physical Activity Intentions of Young People.” Journal of Sport Sciences 19 (9): 711-25.

[17] Ministry of Education. 2011. DEPPS-A.P.S. for Kindergarten. Accessed March 15, 2016. http://www.pi-school.gr

[18] Zimmer, R. 2007. Handbook of Kinetic Education: From Theory to Practice. Athens: Athlotypo.

[19] Biddle, S. J. H., Gorely, T., and Stensel, D. J. 2004. "Health-Enhancing Physical Activity and Sedentary Behavior in Children and Adolescents." Journal of Sports Sciences 22 (8): 679-701.

[20] Tieman, B. L., Palisano, P., and Sutlive, A. C. 2005. "Assessment of Motor Development and Function in Preschool Children." Mental Retardation and Developmental Disabilities Research Review 11 (3): 189-96.

[21] Kambas, A., Venetsanou, F., Giannakidou, D., Fatouros, I., Avloniti, A., Chatzinikolaou, A., Draganidis, D., and Zimmer, R. 2012. "The Motor-Proficiency-Test for Children between 4 and 6 Years of Age (MOT 4-6): An Investigation of Its Suitability in Greece." Research in Developmental Disabilities 33 (5): 1626-32.

[22] Zimmer, R., and Volkamer, M. 1987. Motor Test for Children Aged 4 to Six Years Old: MOT 4-6; Manual/MOT 4-6. Revised and Expanded Edition.

[23] Kambas, A., Gourgoulis, B., Fatouros, I., Aggeloussis, N., Proviadaki, E., and Taxildaris, K. 2005. "The Influence of 
a Psychomotor Education Program on Motor Performance in Preschool Children." Hellenic Journal of Physical Education and Sport Sciences 56: 49-59.

[24] Kostantelia, N., and Tsapakidou, A. 2009. "Motor Development and Understanding of Shapes and Solids within an Interdisciplinary Program in Kindergarten." In Proceedings of the 6th National Conference on Science Education and ICT in Education. Pedagogical University of Western Macedonia, Florina: 462-9.

[25] Zaragkas, Ch. 2013. "Kinetic Performance of Infants and Its Relationship with the Indicators of Body Development." Practical Scientific Yearbook Early Childhood Department University of Ioannina School of Education (6): 160-201.

[26] Papadopoulos, D., Kambas, A., Christoforidis, Ch., Fatouros, I., and Taxildaris, K. 2007. "Comparative Study of the Kinetic Performance of Preschool Children from Greece and Germany by Using Package Evaluation "Karlsruher Motorik-Screening" (KMS 3-6)." Inquiries in Sport \& Physical Education Volume 5 (1): 72-81.

[27] Castetbon, K., and Andreyeva, T. 2012. "Obesity and Motor Skills among 4 to 6-Year-Old Children in the United States: Nationally-Representative Surveys." BioMedCentral Pediatric 12: 28. Accessed March 15, 2016.

http://bmcpediatr.biomedcentral.com/articles/10.1186/14 71-2431-12-28

[28] Morano, M., Colella, D., and Caroli, M. 2011. "Gross Motor Skill Performance in a Sample of Overweight and non-Overweight Preschool Children." International Journal of Pediatric Obesity 6 (2): 42-6. Accessed March 21 , 2016. https://www.ncbi.nlm.nih.gov/pubmed/21923296

[29] Roberts, D., Veneri, D., Decker, R., and Gannotti, M. 2012. "Weight Status and Gross Motor Skill in Kindergarten Children." Journal of Pediatric Physical Therapy 24 (4): 353-60.

[30] Shi, Z. M., Zhou, J. H., Wang, A. H., and Wang, A. L. 2013. "Z Scores for Growth and Development, Physical Fitness, and the Relationship between Them in 362 Preschool Children in Yantai City, China." Zhongguo Dang Dai Er Ke Za Zhi 15 (2): 125-8.

[31] Trinh, A., Campbell, M., Ukoumunne, O. C., Gerner, B., and Wake, M. 2013. "Physical Activity and 3-Year BMI Change in Overweight and Obese Children." Journal of Pediatrics: 131 (2): e470-7. Accessed February 10, 2016. http://pediatrics.aappublications.org/content/131/2/e470

[32] Gavrilov, Y., Rotem, S., Ofek, R., and Geva, R. 2012.
"Socio-cultural Effects on Children's Initiation of Joint Attention." Human Neuroscience 6, Article 00286. doi:10.3389/fnhum.2012.00286.

[33] Melis, A., Floedl, A., and Tomasello, M. 2015. "Non-egalitarian Allocations among Preschool Peers in a Face to Face Bargaining Task." Journal Pone 10 (3): e0120494. Accessed March 15, 2016. http://dx.doi.org/10.1371/journal.pone.0120494

[34] Moriguchi, Y. 2014. "The Early Development of Executive Function and Its Relation to Social Interaction: A Brief Review.” Frontiers in Psychology 29 (5): 388.

[35] Wilson, B. J. 2003. "The Role of Attentional Processes in Children's Prosocial Behavior with Peers: Attention Shifting and Emotion." Development Psychopathology 15 (2): 313-29.

[36] Pless, M., Carlsoon, M., Sundelin, C., and Persson, K. 2001. "Pre-school Children with Developmental Co-ordination Disorder: Self-Perceived Competence and Group Motor Skill Intervention.” Acta Paediatric 90 (5): 532-8.

[37] Ruizj, M., Graupera, J., Gutiérrez, M., and Miyahara, M. 2003. "The Assessment of Motor Coordination in Children with the Movement ABC Test: A Comparative Study among Japan, USA and Spain.” International Journal of Applied Sport Sciences 15 (1): 22-35.

[38] Pappas, Chr. Ed. 2006. The Influence of Social Developments in Children's Life and Mobility. Athens: Gutenberg.

[39] Bruininks, R. 1978. Bruininks Oseretsky Test of Motor Proficiency: Examiners Manual. Minnesota: American Guidance Service.

[40] Papadopoulos, D., Fatouros, I., and Taxildaris, K. 2008. Motor Proficiency, Physical Activity and Body Mass Index in Preschool Aged Children. European Psychomotricity Journal 1 (1): 61-6. Accessed February 10 , 2016. http://www.psychomotor.gr/contents/archive-vol1,-2008/ special-issue/35-motor-proficiency-physical-activity-andbody-mass-index-in-preschool-aged-children.html

[41] Vameghi, R., Shams, A., and Shamsipour-Dehkordi, P. 2013. "The Effect of Age, Sex and Obesity on Fundamental Motor Skills among 4 to 6 Years-Old Children.” Pakistan Journal of Medical Sciences 29 (2): 586-9.

[42] Giagounidis, P. 1996. The Preschool Education in EU Countries. Thessaloniki: Code.

[43] Pantazis, Sp. Ed. 1997. Pedagogies and Game Object in the Nursery Room. Athens: Gutenberg. 